\title{
Multilingual Approach to Mathematics Education
}

\author{
Shailaja Bairy ${ }^{1,2}$ \\ ${ }^{1}$ Madhava Kripa School, Manipal, Karnataka-576104, India \\ ${ }^{2}$ Department of European Studies, Manipal Academy of Higher Education, Manipal, Karnataka-576104, India \\ Email: msshailajabairy@gmail.com
}

\section{ARTICLE INFORMATION}

Received: May 31, 2019

Revised: July 18, 2019

Accepted: August 28, 2019

Published Online: September 04, 2019

Keywords:

CLIL, Plurilingualism, Singapore Bar Model Method

DOI: 10.15415 /iie.2019.72008

\begin{abstract}
Multilingual approach to pedagogical practices in mathematics has the potential to target high level mathematical competence and abstraction. Content and Language Integrated Learning (CLIL) is an innovative educational approach to learning, a dynamic and motivating force with holistic features. Not only does it image a shift towards curricular and cultural integration but also helps greatly to focus on deeper conceptual understanding in Mathematics. CLIL's basic principle of integration of the content and languages if accepted in a broader sense as 'Content connected to regional language and a new language, culture, nature, real-life' might solve various problems associated with the teaching-learning of mathematics, and thus ensures to support 'learning for real life'. This paper establishes the need for 'Multilingualism' through a comprehensive literature research. It highlights multilingualism as a trigger for active approach to the quality of Mathematics education, mainly in Indian scenario. The importance of teaching mathematics as a language and specific strategies for teaching mathematics vocabulary are discussed. The illustrations provided for such approaches are entirely based on author's teaching experiences.
\end{abstract}

\section{Introduction}

Globalization has changed the education scenario of today. Exploration of change \& exponential growth of technology are transformed today's societies worldwide into multicultural and multilingual societies and today's demand is holistic education. The new trends that are drawn from this are: Integrated approach to teaching, using a second or foreign language as a means of instruction (Multilingual approach to teaching), amalgamating innovative methods to enrich classroom experiences.

Mathematics holds a significant place in modern society as it is the major ingredient of any output in pure and applied sciences in STEM education. Being an important segment of formal education, several leading educational committee reports highlighted the significance of mathematical knowledge and its value. In spite of this, the issue of poor achievement, innovation still persists in the field of mathematics education.

\section{Context}

\subsection{Why Content Language Integration in Learning? Why Multilingualism?}

Mathematics is an integral part of the human lifestyle and it possesses its own language, symbols, terminology, technology, and methods. Globally, each society has its own mathematical languages, counting system, symbols, and terms. According to Gardella and Tong (1999), there are huge similarities between the learning of mathematics and language acquisition. (Hofmannova, Novotna \& Moschkovich, 2004) Mathematics deploys non-verbal communication, visual, and graphic technique. Mathematical language owns a grammatical structure of a distinctive type and is rich in vocabulary. The vocabulary in mathematics remains the same and is not bound by languages across countries. The National Research Council (2012) asserted that learning of mathematics is deeper only when students build their own mathematical understanding through examination, representation, transformation, solving, application, proving, and above all communication in a multilingual set up. Thus, teaching mathematics requires not only precise conceptualization of the subject matter but also appropriate adaptive strategies that support the construction of fundamental mathematical knowledge. 
Language serves as a coherent means of communication, and proficiency in multiple languages distinctly paves the way for the learning of subjects. $21^{\text {st }}$ century pedagogical approach depends on a languagerich classroom and communicative competence in learners; this makes it mandatory that the mathematics is effectively integrated with languages. To enrich grass root knowledge, empower creativity, and promote collaboration across the disciplines, innovative educators started a movement to integrate A (Arts: humanities, language arts, dance, drama, music, visual arts, design, human culture, and new media and design) into STEM. The first known revolutionary look towards centralization of the integrated approach to education was of Friedrich Froebel, a German educator and the inventor of kindergarten. In 1830, he laid foundations to STEAM, long before the acronym. Further, Georgette Yakman developed the STEAM educational framework in 2006, which includes a way for all the subjects to connect with each other and a rapidly changing world for developing reality-based lifelong learning skills. Leeuwen, Vovers \& Silk (2018) explain the importance of STEAM across the wider curriculum as 'The concept STEAM replacing STEM in $21^{\text {st }}$ century is the foundational global movement that possesses potential to demand a paradigm shift in teaching learning process'.

The following figure represents $21^{\text {st }}$ century student skills as mentioned by Mishra \& Mehta (2017).



Figure 1: $21^{\text {st }}$ century student skills and outcomes.

\section{Research Questions}

What are the implications of the existing theories that support mother tongue based multilingual Mathematics education?
1) What are the various linguistic factors that are proved to contribute to the 'Conceptual understanding' in mathematics?

2) Which are the specific educational strategies that support teaching of mathematics vocabulary in a multilingual set up?

\section{Rationale for the Study}

Being in a transformational state, today's multicultural and multilingual society demands a holistic education. Education with a holistic outlook is connected with the expansion of every person's creative, social, intellectual, physical, emotional, artistic, and spiritual capabilities. It explores the possibilities of involving students in the teaching-learning process and boosts the inculcation of personal and collective responsibilities in them. Marsh, D. (2012) and Marsh, D., \& Martín, M.J.F. (2012) transformational educational approach CLIL (Content and Language Integrated Learning, originated in 1994) represents a bilingual access to the teaching of a core subject, through integration of innovative and enriching methods. It images a shift towards curricular and cultural integration, greatly helping focusing on a deeper conceptual understanding of subjects like mathematics. CLIL thus acts as a catalyst of change and the primary vision of CLIL is to prove as a best pedagogical practice that can accommodate the linguistic diversity present in different countries and use it for upgrading the quality of learning core subjects. CLIL's basic principle of integration of the content and languages if accepted in a broader sense as 'Content connected to regional language and a new language, culture, nature, real-life' might solve various problems associated with the teaching-learning of mathematics, and thus ensures to support 'learning for real life'.

National Centre for Biotechnological Information (NCBI, a branch of the National Institutes of Health in the US) has proved that multilingual children have several cognitive, emotional, and cultural advantages over monolingual children. In India where improvements in access to education often come at the cost of loss of a language i.e., since language taught at school and the language spoken at home are different, multilingual education plays a vital role. This approach is useful in balancing the need for a business language, such as English, alongside the benefits of a mother 
tongue-based learning. It is broadly demonstrated that future-ready employees need to possess multiple areas of competence or at least appreciate the ways a spectrum of skills and cultures fit together. The basic principle of multilingual approach to mathematics teaching being the cross curricular approach to education, teachers often focus on students making connections between mathematical concepts and solving problems in innovative and exciting ways (creative problem solving). Students demonstrate this by an active engagement (cooperative learning) with their discoveries being perceivable in enthusiastic "Wow" moments. Children who grow up to be proficient in more than one language experience long term and significant cognitive, psychological, and cultural advantages. These advantages include a keener sense of self-expression, the ability to empathise with and learn from different people, and better professional skills later in life.

The problem (Limitations of Indian education system):

a) As per the review by the National Education Policy (2019), school curriculum is not lined up with our National Curriculum Framework (NCF) and hence, we experience a drop in quality though we have shown improvement in access and equity.

b) Current mathematics curriculum initiatives in India are strongly influenced by globalization and the major shift towards English medium schools. The rise of English as a medium of instruction has led to its dominance over other national languages. The resulting linguistic tensions and chauvinism has built barriers between subjects.

c) Low mathematical competency in students (in board exams, competitive exams, decline in discoveries and research) due to a 'lack of conceptual understanding' of mathematical principles, leading to negative attitude towards the subject.

d) The first and second languages of study are not at a proficiency level when students enter Middle school. Hence, the class becomes linguistically heterogeneous (reasons being incompetent or nonnative teachers, less focus on Three Language Formula in primary classes, 'Only English' rule in English medium schools, ignorance of multilingualism by school community, and lack of interdisciplinary and innovative approaches).

e) Inadequate student preparation for facing 'The abstraction of mathematical concepts and formalism', introduction of subject-wise specialised teachers from middle school makes comprehension further difficult. f) Stressing on the above mentioned negative points, NEP 2019 clearly states the importance of understanding the flexibility of the Three Language Formula in schools and its role in breaking the barrier between Sciences and Languages, STEM to integrate with Arts and Humanities, and innovative teaching to target holistic education. To focus on the deeper conceptual understanding through the use of innovative techniques, NEP 2019 planned to shrink the curriculum content to its core.

\section{Research Objectives}

1) To study the existing theories that support mother tongue based multilingual Mathematics education

2) To conduct a comprehensive literature research on thecontributing linguistic factors to 'Conceptualisation in mathematics'

3) To illustrate the specific educational practices that support teaching of mathematics vocabulary in a multilingual set up.

\section{Theoretical Framework}

Introduction: In education, diversity takes the form of students arriving with a life trajectory characterised by a plurality of languages and culture, which is seen either as a problem or as an asset (Piccardo et al., 2017). Language is on the front-line as the languages and cultures of migrants interact with the languages and cultures of host societies. This paves the way for a change, with language acting as the potential catalyst. This explains the necessity to focus on linking multilingualism, cognition, and creativity.

\subsection{Result of Literature Review of Key Concepts}

\subsubsection{Multilingual Education and Mathematics}

Serving as a medium of communication, a language also acts as an instrument of information processing, organization, storing, and interconnecting. The oral expressions of anindividual are directlyand closely linked to one's mental images. Speech constantly interacts with cognitive process. (Novotna \& Hofmannova, 2002). The influence of the mother tongue on one's thought process \& perception is abundant. Different languages contribute to the structuring of all notions of a person and the formation of mental schemata. The meanings are attached to the mental schemata and the real world is interpreted and viewed (Jean Piaget's 
theory of cognitive development) by an individual. As a person's perception and expression both link to his linguistic abilities, the learner's orientation in society is also defined, established, and greatly enabled by his mother tongue. Mother tongue and regional language is an operative medium with syntactic and grammatical structure, and is a highly developed channel of communication used in the social environment.

The ease of learning mathematics is probably directly proportional to the comprehension of basic language of instruction. Vocabulary understanding, thus, is the major contributor to comprehension. Hence, to develop mathematical proficiency, comprehension of the language of instruction and the language of mathematics is a prerequisite. The positive influences of teaching mathematics simultaneously through mother tongue and secondary language are plenty. Multilingualism facilitates the development of cognitive processes through conceptualization.

According to a research by neuroscientists of University of California, San Francisco, (2016) language involves both sides of the brain. Children learn languages more easily because the plasticity of their developing brains lets them use both hemispheres in the language acquisition. Crosstalk between left and right brain is the key to language development. Possessing the ability to speak multiple languages develops one's brain in various ways. If a language is learnt early enough, both the brain hemispheres gain strength. And as the left side of the brain is favoured for analytical and logical functions, and the right side is favoured for emotional and social functions, learning a language early gives comprehension efficiency and cultural empathy. There exists a higher density of gray matter in a multilingual brain (Nacomulli, 2017).

\subsubsection{Plurilingualism}

Multilingualism constitutes the presence of more than two languages within a single speaker. Plurilingualism, the interconnected knowledge of multiple languages, is seen as a catalyst for creative learning in today's superdiverse society. It promotes the awareness of language diversity, functional uses of a variety of linguistic means, recognition of similarities and differences among languages, and the link between language and culture(s) and eventually also the link between the specific features of each language, including the mother tongue (Piccardo, 2013).
In a country like India, multilingual competence comes easily to children, and it is imperative now that we capitalise on the distinct feature of our multilingual situation and turn it into a classroom resource. Figure 2 illustrates the connectivity of various languages to the central theme 'conceptualization based multilingual teaching of mathematics'.

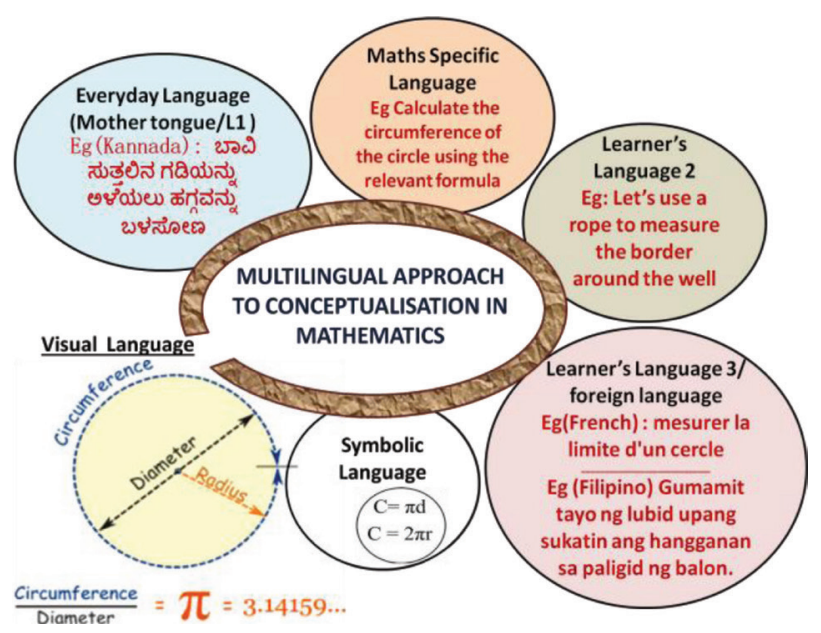

Figure 2: Schematic representation of 'conceptualization based multilingual mathematics teaching'.

\subsubsection{Teaching for 'Conceptualization' in Mathematics}

Teaching is reaching. The National Council of Teachers of Mathematics (NCTM) (2000) states that "Communication is an essential part of mathematics and mathematics education". It refers to mathematics as a language of communication, and emphasises on the Standards for School Mathematics that "Instructional programs from pre-kindergarten through grade 12 should enable all students to: communicate their mathematical thinking coherently and clearly to peers, teachers and others and use the language of mathematics to express mathematical ideas". In fact, communication is one of the five process standards emphasised by NCTM. Cooke \& Buchholz, (2005) reiterated the above points and determined that teachers must necessarily create a link between mathematics and language (Cooke \& Buchholz, 2005).

'Conceptualisation in mathematics' refers to teaching a concept to help students develop a deep understanding of mathematical principle and its underlying process, thereby identify the connection 
between multiple concepts (SEDL) (Molina \& Wackwitz, 2012). Hence, the mathematical communication involved in the process of teaching mathematics should enhance a student's accessibility to the thinking of criteria relating to theory-building, problem-solving, and learning strategies that underpin the development of the mentioned mathematical knowledge.

\subsubsection{Code Switching}

The linguistic capabilities and linguistic choices of the person addressing and teaching a bilingual student are the most noteworthy variables for the student's language choice. Number talks (or 'math talks') are short discussions between a teacher and students on how to solve a particular mathematics problem. The focus is not on the correct answer, but on all the possible methods of finding the answer. During any mathematical computations or interactive sessions (Number talks) bilingual students often prefer to switch languages. Code-switching can be spontaneous, rapid, and highly natural, and it will smoothen the solving of word problems. However, the language proficiency of the student is supposed to suffice for comprehending the text of the word problem. Code-switching is noted as a valuable educational resource and it serves as a means of fostering mathematical understanding of the students (Setati, 1998; Adler, 1998; Moschkovich, 2005; Zazkis, 2000).

In a multilingual classroom, it is the teacher's role to harness language as a resource and assist learners' movement back and forth between their main language and the language of instruction on the one hand, and on the other hand, between every day, educational, and mathematical discourses (Adler, 1996).

\subsubsection{Mathematical Discourse}

Language is a critical element of teaching and learning. It is the medium through which information is conveyed and through which an instructor is able to determine whether or not students grasp the concepts and skills taught (DiCerbo, Anstrom, Baker \& Rivera, 2014). Communication or discourse is one of the key factors in building an understanding in the mathematics classroom of the $21^{\text {st }}$ century. Star \& Stylianides (2012) stated that conceptual understanding and procedural knowledge are the foundations of mathematical reasoning. Teaching techniques would therefore benefit from widening the range of mathematics discourse to include conceptual knowledge and procedural understanding. A Vygotskian viewpoint, as articulated by Gibbons (2006), suggests that language use through interaction is at the root of learning, which not only shapes students' talk, but also helps in constructing understanding (Research review by NCTM, 2013). Brantlinger (2014) suggested that mathematics discourse, involving explanation, argumentation, and defense of mathematical concepts, should be a defining feature of a quality mathematics classroom experience for English Language Learners, since academic language can increase the difficulty of mathematics items for ELLs. The National Academies for STEM learning, (2018) insisting on transforming education, states that students learn to think mathematically through participating in productive mathematical discourse in classrooms. Mathematics is best learned through discourse; discussion gives students the opportunity to explore mathematical concepts and develop an understanding of concepts that otherwise might seem abstract to them.

\subsection{Psychological Background}

Mathematics education in India has experienced a drastic shift from regional language medium to English medium. However, the student body is multicultural and widely varied, academically. Sarama, Lange, Clements \& Wolfe (2012) suggested that students who live in poverty and who belong to linguistic and ethnic minority groups clearly show proportionally lower levels of linguistic skills (especially English) and academic achievement. Vygotsky's socio-cultural theoretical framework is relevant to this study. Vygotsky (1978) noted that, "Cognitive development occurs as the result of meaningful verbal interaction between novices and more knowledgeable interlocutors such as parents, peers, or teachers". According to Darhower (2002), "The socio-cultural theory operates on the assumption that human cognitive development is highly dependent upon the social context within which it takes place". Closely linked to the Vygotskian view of cognitive development is the concept of shared view. Darhower suggested that, "Engaging in collaborative discourse requires a shared communicative context" i.e., speakers who have the same kind of experiences and social circumstances can readily share their lived experience. Henry, Nistor \& Baltes (2014) have 
shown that active parental involvement stimulated a higher literacy development in students, a greater understanding of the subject matter, an expansive background knowledge, and a higher language proficiency. Vygotsky's sociocultural theory ascertains the same and suggests that the acquisition of deeper knowledge or skill occurs with social communication and comprehension as a result of socialization (Steiner, \& Mahn, 1996). This theory encourages the teaching of mathematics around students' cultural identities, which makes mathematics accessible to those who have traditionally had difficulty learning the subject.

\subsection{The Relevant Themes Explored from Broader Educational Domain}

\subsubsection{National Education Policy 2019 (revised) Highlights in its Review}

Pointing to the need for linking subject with native language, NEP quotes, "Usually when teachers are not from local region, the language barriers often exist between the teachers and students". If students struggle to absorb the language through which they are taught, evidently, the core subject using the same language to build its knowledge also becomes tough, making them lose interest. Low learning outcomes lead to the decline of interest in the subject. The language in which students are most comfortable must be used to teach the core subject.

Mentioning on Reform in Curriculum and Pedagogy in Schools, NEP points to a transformation in curriculum and pedagogy to make it more spirited, application oriented, and engaging, with the prime concern to attain universal foundational literacy and numeracy by year 2025 . This must aid the minimization of rote learning and also aim at a holistic development, and fit into the modern age to enhance creativity, scientific temper, critical thinking, collaboration, problem solving, communication, multilingualism, and ethical learning. Students are exposed to formalisms in middle school ( $\mathrm{Gr} 6$ to $\mathrm{Gr}$ 8 ), wherein each subject teacher moves towards more abstract concepts, and hence, this transition must be made smooth. Introduction of more specific subjects and its branches across the sciences, mathematics, humanities, arts, and social sciences must be appropriately supported by helping students get the maximum out of the experiential learning within each subject, and the spirited exploration of inter and intra connectivity among various subjects. NEP clearly mentions, "No separation of subjects"; the boundary between subjects (arts, humanities, sciences, and social sciences) should be erased and students must be given equal opportunities to engage in all subjects. Targeting a deeper understanding and clarity of concepts compulsorily provides opportunities for analysis, discussion, questioning, and application through interactions, fun based/collaborative/exploratory activities in class.

\subsubsection{Theories and Documents that Support Education in Local Language and Multilingualism}

Language stands as the basic tool for expressions of an individual or for communication and is a building block of one's cognitive, cultural, and social potentials. Not only does it mediate knowledge reception and production but it also provides a collective continuity to social culture. The science of child development and language learning has proved that learning is best when taught in mother tongue. The flexibility to learn multiple languages is high between the ages 2 to 8 years. Plurilingualism acts as a stepping stone to creative learning in super diverse society (Piccardo, 2017; Piccardo, 2013). This social tendency, if used rightly for the benefit of education, can work wonders. At present, a large number of students are going to schools where the teaching is carried out in a language totally or partially unfamiliar to them. This gap, with reference to language comprehension, causes students to lag generally in all subjects, right from the start. The standards and quality of textbooks (written in Indian languages) do not match those written originally in English. The NEP 2019 proposed a new curriculum, which promotes a flexible language approach in teaching learning process and encourages multilingualism.

\subsubsection{Theories that Explain "Why Mathematics is a Language?"}

Italian astronomer and physicist Galileo Galilei calls mathematics the language of the universe, and numbers and symbols as its script. The universe can be comprehended and understood thoroughly only through the learning of its language (mathematics). To learn the language of mathematics, one needs to be familiar with the script in which it is written. The 
script refers to the triangles, circles, and geometrical figures, and most of all, numbers. As mathematics satisfies all essentials of a language, it can be considered as a language for several reasons. The script it uses is common to the entire world. The characters, symbol and their indications, syntax, and grammar are fixed.

Mathematics is used to communicate the scientific language, often by scientists, mathematicians, and others who deal with it. Mathematics describes itself (meta mathematics) as well as the phenomena of nature, practical world, and abstract concepts. Other languages might have differences in the aspect of writing the script from left to right or right to left, etc., whereas mathematics is written left to right. Its vocabulary includes numerals, alphabets from different languages, and symbols those that are exclusive to mathematics. A mathematical equation can be transformed into a word statement (a sentence form) using appropriate noun and verbs, very similar to that of a sentence in any other language. Efforts made to grasp the ways in which mathematical sentence works will help the absorption of mathematics concepts. This process must be inevitably integrated with one's familiar language, and on the whole, can be compared to translating a foreign language to one's basic or original language.

Ways to enhance mathematics language: Successful teaching of mathematics lies in aiding the development of its language through techniques that focus on the learning of concepts and ideas that connect: how things work and how they mutually relate, using the most relevant vocabulary (Riccomini, Smith, Hughes $\&$ Fries, 2015). The connection between the language of mathematics and language of instruction thus seems to be deeply interwoven and the 'concept building' in mathematics is geared up only when the instructional languages are carefully enriched to step up to abstract contexts. The language enrichment also becomes successful when it is done in a relevant context. When focused on in a parallel manner, both content and language flourish. The two-fold focus gives multiple opportunities for the reprocessing of concepts, grammar, and related vocabulary. The accelerated knowledge-gain brings in rich vocabulary and grammar in both content (mathematics) and language learning areas. Valid meanings are constructed linguistically at the discourse level. Explicitly, the interdependence between 'the language used' and 'the mathematical content explored' is used for their own mutual benefits. Hence, teachers must consider the language demands of a subject as promising opportunities to develop the mathematical communication abilities in students, instead of seeing them as barriers (Kelly, Doerr, Hinchman \& Masingila, 2015).

\subsubsection{Theories on Efficiency of CLIL Approach in Stabilizing or Targeting the Conceptualization}

The construction of knowledge takes place through 'languages of schooling' i.e., the languages all students study, relate to and communicate in during their education (de Craen, Surmont, Knell, Stroughmayer \& Struys, 2017; Moe, 2017). With its dual focus, CLIL ably generates and catalyses 'methods of teaching language' as well as the didactic teaching of the content. Mehisto (2008) mentions that the core features of CLIL methodology are: its multiple focuses, authenticity, enriching and safe learning zone, active learning, and scaffolding. According to Mehisto, scaffolding refers to building on students' extant knowledge, practical talents and dexterity, fostering creative and critical thinking, responding to different learning styles, and challenging the students to take a step forward. CLIL provides opportunities to conceptualise, and encourages investigating and learning content through different outlooks and perspectives, facilitates access to subject-specific target language terminology and makes students ready for future studies and a working life.

\subsubsection{Theories on Language Factors Involved in Mathematics (As a Language Itself) Education}

Mathematics is a field of study where communication through non-verbal and visual forms, technology, and graphic materials are extensively used. The language of mathematics possesses a conventional grammatical structure, and is abundant in words that are limited to this specific field. Mathematics has a specific register, vocabulary, and set of discourses that are similar to many languages. In spite of the fact that for more than forty years the language factors affecting mathematics have been studied, the first momentous input to this topic perhaps is that of Brune (1953), their comprehensive research began only after 1980 . The term "language factors in mathematics learning" has been referred to several times by psycholinguistics and sociolinguistics for the classroom communication in bilingual classes.

According to Hejný (2012), the issue of concern is 'the surface knowledge of the mathematics 
concepts leading to formalism' (Referring to 'formal' understanding (learnt superficially, without deep understanding). He mentions, that language of mathematics is an arbitrary system of signs by means of which, the realization of thinking and communication is carried out. i.e How the images and thoughts (concepts) are transformed into their corresponding linguistic representations (mathematical language), is 'the point on focus' during the teaching of mathematics. Any possible deficiency at any stage might impair the transformation mentioned above. The words and signs assigned with - wrong conceptions and ideas, absent conceptions, and failure to form linguistic representation for a conception - these impair the relationship between concept formation and construction of mathematical language or knowledge.

Pimm, \& Keynes (1994) mention that the mathematical language can refer to: ${ }^{*}$ Language of communication in a mathematics classroom, ${ }^{*}$ The vocabulary used for mathematical ends (mathematics register), *Specific language of mathematics textbooks, and ${ }^{*}$ The symbolic language in written form. Language of mathematics, in a broader sense, indicates the inner self speech (language exclusively used by an individual during problem solving) and communicative speech during problem solving (person to person). Using the languages in the most suitable manner, the mental images can be both conjured up and controlled in the service of mathematics.

Research work by Gardella \& Tong (2002) and Clare Lee (2006), considering the spectrum of 'language development (both mathematical language and communicative language)' under the investigation of mathematical learning, throws light on "The ways in which one's linguistic expressions can expedite and promote the preliminary acquisition and communication of basic concepts and skills by aiding children conceive, construct their conceptualization of mathematics adopting language they comprehend". Considering this as the foundation, they can further proceed to mathematical symbolism, which represents the most refined level of communication.

The process of 'teaching-learning mathematics' involves oral language (listening and discussing) along with its written form (activities of reading and writing). The educational approaches to the language of mathematics largely vary from the access to ordinary communication. Though mathematics requires precise instructions during its teaching, due to the usage of several verbal and nonverbal ways of illustrated explanations (namely exemplification, rephrasing, analogies, body language, gesture, repetition, representation, and visualization), enhancement of both receptive and productive skills of associated languages is ensured. The use of interactive strategies, which focus more on learner's comprehension and feedback, become a part of the teaching (Glasersfeld, 1995).

\section{Research Gaps}

Bilingualism is an area that poses a number of challenges for researchers. According to Benson, mother tongue based bilingual education has positive implications for increasing access to education and improving its quality. (Benson, 2004; Benson 2016). Bilingual models and practices differ from place to place. The educational arena in India demonstrates one of the most complex and intricate multilingual atmospheres. For example, in India, children are taught the language of the state as well as English. Now, both these languages occupy a hegemonic position in societies. Since a decade, the mass 'switch over' from the mother tongue medium to the English medium has significantly increased the struggles a student undergoes to digest the concepts in core subjects. The receptive and productive skills in the secondary language are in decline. In an Indian multilingual classroom, students with different mother tongues (Eg: Tulu, Kannada, Konkani, Hindi) come together to study all subjects in either English medium or regional language medium. The parent community of English medium school students is conversant in English at varying degrees, but encourages their children to pick up English more than other languages. The regional language is taught as a language but not encouraged as a medium though the ground reality is that students are at better comprehension levels in their regional language rather than in English. Colin Baker quotes in his book 'Foundations of bilingual education and bilingualism', "With the rapid spread of information technology and networked information has gone the rapid spread of English. The inherent danger is that minority languages, cultural diversity and bilingualism therefore come under threat" (Baker, 2011). 
Contrary to popular assumption, language plays a critical role in learning and comprehending mathematics. Past studies have demonstrated the role that language proficiency plays in learning mathematics (National Academies of Sciences, Engineering and Medicine 2018; Henry, Nistor \& Baltes, 2014). It is true that the mathematics-phobia in children often roots to poor conceptual understanding. Today's teachers are challenged to make mathematics lessons comprehensible and ensure that students subsequently gain proficiency in the languages used in mathematical communication and language of mathematics to understand classroom instruction and efficiently express their grasp of mathematical concepts orally and in writing. Available research in the area of bilingual approach to mathematics teaching hardly finds a place in the Indian context. Bilingual approach aiming conceptualization through deeper mathematical comprehension also requires professional skill development of the teachers. This is an unexplored area.

Limited studies have been carried out generally to address the following educational issues in Indian multilingual scenario:

- The learning crisis in our country persists both at 'Foundational stage (age up to 8)' and 'Elementary stage (including middle and high school)'. Quality education is neither ubiquitous nor everyone's cup of tea. The school curriculum (considering vision, aims, academic learning content, and the teaching learning process) are not lined up with the National Curriculum Framework and State Curriculum Framework. Also, it doesn't promote holistic development and $21^{\text {st }}$ century skills (collaboration, problem solving, critical thinking, creativity, communication, scientific temper, multilingualism, ethical and social responsibility, inquisitiveness, and digital literacy).

- There exist linguistic tensions in the form of medium of instruction issues, dominance in $2 \mathrm{~L}$ and $3 \mathrm{~L}$ status, and linguistic chauvinism, which tend to hamper academic harmony. This results in building of barriers between two distinct subjects of study.

- The presence of inconsistencies and variations in the implementation of the three language formula in schools in India, due to an inability in understanding the flexibility in the formula.

- Lacuna in the field of innovations in multilingual approach and research resolved to enhance the quality of mathematics teaching in Indian schools.
- Insensitivity in educational community with regard to the need for focusing on holistic education and its relevance to global education.

Extraction of the basic golden principles of our Gurukula system to modern education is not tried out.

\section{Reflection on Action Research}

The illustration of the specific educational practices that support teaching of mathematics vocabulary in a multilingual set up is based on exploration of the research topic in the light of past teaching experiences of the author. These have been expressed at various international conferences. The following are the extracts of some action research taken up by the author which provide an insight into various multilingual approaches that connect to mathematics education.

\subsection{Specific Strategies for Teaching Mathematics Vocabulary:}

\subsubsection{Creation of Bilingual Mathematics Dictionary}

e-Display Charts, Resource vocabulary banks (In video or audio forms) that contain bilingual mathematical vocabulary, words and phrases along with the illustrated usages. These words are to be accompanied by pictorial illustrations. These help enhance mathematical thinking.

\subsubsection{Error Analysis and Tracing Through Multilingual Approach}

The teaching strategies that support the construction of basic mathematical knowledge must address common mistakes those often rooted to poor understanding of math concepts. At higher primary level, when algebra is introduced, the students are exposed to a variety of algebraic expressions and equations. Various new concepts (Eg: Percentage, Exponents, Rational numbers, and Graph theories) too are introduced. Several word problems are complexly stated. The 'type of the mathematical problem' gradually shifts to 'application based' and becomes purely, partially abstract. The lack of conceptual understanding thus leads to major misconceptions and 'the mathematical difficulty' thus produced, generates 'math- phobia'. This makes 'Specific mathematical language' incomprehensible for students. The 'struggles' a student undergoes to digest the concepts,significantly 
can be minimised by effectually focusing on diagnosis and treating mathematical difficulties and the misconceptions. A multilingual approach is essential to teach the subject conceptually through the technique of error analysis and tracing.

Eg1: Consider $8 \mathrm{~m}-\mathrm{m}$. Here, students rarely visualize the coefficient of $\mathrm{m}$ as 1 . They reach at the answer $8 \mathrm{~m}$, as they consider $\mathrm{m}$ as zero times $\mathrm{m}$. Similarly when given the expression $8 m-8$. They hardly identify the common factor 8 and write it as $8(\mathrm{~m}-1)$

Eg 2: How much is $(2 m-7 n)$ more than $(-7 m-5 n)$ ?

By How much is $(2 m-7 n)$ more than $(-7 m-5 n)$ ?

The above two problems are different from each other, but the framing is such that, one who is not very good in grammar cannot understand it and interpret correctly.

After a comprehensive study and analysis of students' common errors, teacher prepares a formal document (with samples of major erroneous exercises and worksheets to explain and address the mistakes or misconceptions). The method requires application of didactically adapted intentional multilingual corrective teaching, in addition to regular teaching. A cooperative learning atmosphere which encourages multilingual mathematical conversations is the fundamental necessity. A set of solved sums with intentional conceptual errors are created and students use these erroneous exercises as advanced work sheets. Also, supportive ICT sources are used as aids in a highly flexible teaching learning atmosphere.

\subsubsection{Mathematical Discourse or Number Talk (Bilingual)}

Number talks play significant role in inducing the number sense in students and help them explore the beauty of mathematics. This eventually ensures to develop a respect for the subject. Integration of mental math techniques to classroom teaching using 'technology aided multi-sensory activities' such as oral quiz, open mental exercise session where student is given chance to explain his logic bilingually in simple words. This initiates in students the notion of the size of the number and provides them with plenty of estimation strategies of their own and they gradually acquire proficiency in logical thinking, applications. Several studies clearly indicate that students with well-developed numerical sense are better able to think logically, critically and flexibly, and they utilize more efficient problem-solving strategies, all of which are vital $21^{\text {st }}$ century skills. In Number talks, students are encouraged to be 'mindful mathematically' before they begin and 'mindful linguistically' as they progress. As students are flexible in their linguistic and mathematical choice of strategies, they can visualize problem solving, perform calculations quickly, and check if their answers make sense. This becomes a beautiful way to orient them to the research in mathematics.

\subsubsection{Using Sentence Frames/Prompts to Support Student Responses}

Math sentence frames serve a variety of purposes. They provide the support for language learners and students involve fully in math discussions called 'Number talks'. These contextualize and bring meaning to vocabulary; provide a structure for practicing and extending language skills. Prompts help language learners to get started, while responding to a question.

\subsubsection{Use of Bilingual Manipulative}

Mathematics content becomes comprehensible when the important tools called 'Manipulatives' are used. These physical objects that are used as teaching aids to engage students in the hands-on learning of mathematics, provide students ways to construct concrete models of 'abstract mathematical concepts'. Thus, manipulatives help enhance students' confidence by giving them an opportunity to test and confirm their reasoning. Being very useful for solving problems, these bilingual aids make mathematics interesting and enjoyable. Strong visual manipulatives such as pictures, demonstration, modeling, role play, video etc help students grasp the language of mathematics, in an efficacious way. They can be used bilingually, during introducing, practice work and remedial teaching of a concept.

\subsubsection{Modified Explanations (Teacher Talk)}

It is important to give explanations by using variety of words for a single concept. Speaking slowly and using clear articulation with necessary intonation, to place stress on important new concepts is equally necessary. Consider the example of teaching 'properties of numbers'. Commutative property of addition/ multiplication $\mathrm{m} \times \mathrm{n}=\mathrm{n} \times \mathrm{m}$. The concept can be 
better understood, if the word meaning of commute is explained as -'Both ways' - 'move to and fro'. This also can be aided by a pictorial representation, as visual language itself acts as an integrating agent. Technology has a great role in this regard. The videos prepared by teachers to illustrate and explain the derivation of a formula or its application serve as valuable resources. In such videos, the key concepts can be illustrated using the demonstration in more than one language (Including language of mathematics), simultaneously. Visual pop-ups in a foreign language will motivate students to pick up the language fast, accelerating its learning.
Similarly, The associative property of addition or multiplication $\mathrm{ax}(\mathrm{b} \times \mathrm{c})=(\mathrm{a} \times \mathrm{b}) \times \mathrm{c}$. The word meaning of associate as 'couple/ connect with something' Distribute-give a share or unit to each of a number of recipients.

Eg: A boss wanted to gift Rs 987 each to his 100 employees. On the day he distributed the amount, 8 were absent. So he distributed Rs 987 x 92 and the balance amount Rs 987x 8 was distributed the next day. Hence 987 x $100=987$ x $92+987 \times 8$

Multiplication using brackets is the best example of distributive property of multiplication over addition. Consider the normal multiplication shown below.

$$
\begin{gathered}
\frac{2759 \times 876}{16554=2759 \times 6} \\
193130=2759 \times 70 \\
\frac{2207200}{2416884}=2759 \times 800 \\
\frac{2}{2759 \times 800)+(2759 \times 70)+(2759 \times 6)} \\
=2759 \times 876
\end{gathered}
$$


Blue Flowers : $8 \times 6$

Orange flowers : $8 \times 2$

TotalFlowers : $8 \times 8=8 \times 6+8 \times 2$

Figure 3: Pictorial representation of 'Distributive property of multiplication over addition'.

\subsubsection{Bilingual Approach to Teaching of Mathematics Concepts- Story Telling Way}

Storytelling in mathematics can be a medium for creating a classroom in which mathematics is appreciated, understood, and enjoyed. Storytelling coupled with bilingualism, aided with technology is very interesting. Use of transcribed dialogue/ narrative, subtitles, translanguaging, as a support to technology (Eg: GeoGebra software useful in mathematics) are the requisites. For a teacher it 
invites: Spotting an appropriate problem or deep mathematical content, creating an interesting story on the concept, planning for bilingual approach and integrating the technology.

Eg: A story for teaching the concept of properties of rational numbers to Grade 8 students-

For Closure property-

Gulliver had set out on his voyage and had reached the land of rational number Lilliputs. He saw that among the Lilliputs, there was a group of Lilliputs who were both integers and rational numbers. A magic box was found there. Two Lilliputs from the integer group jumped into it. They transformed into another integer after the process of addition was performed inside. They fell out and landed into the Integers group itself. Next, two more Lilliputs were taken for subtraction and multiplication. The same thing happened. The next spell was division. Two Lilliputs from integer group jumped in and came out but, they landed in the rational numbers group and didn't belong to the integers group anymore.

Students can be encouraged to make up stories of their own to learn the concept easily. Script writing skill is developed in students.

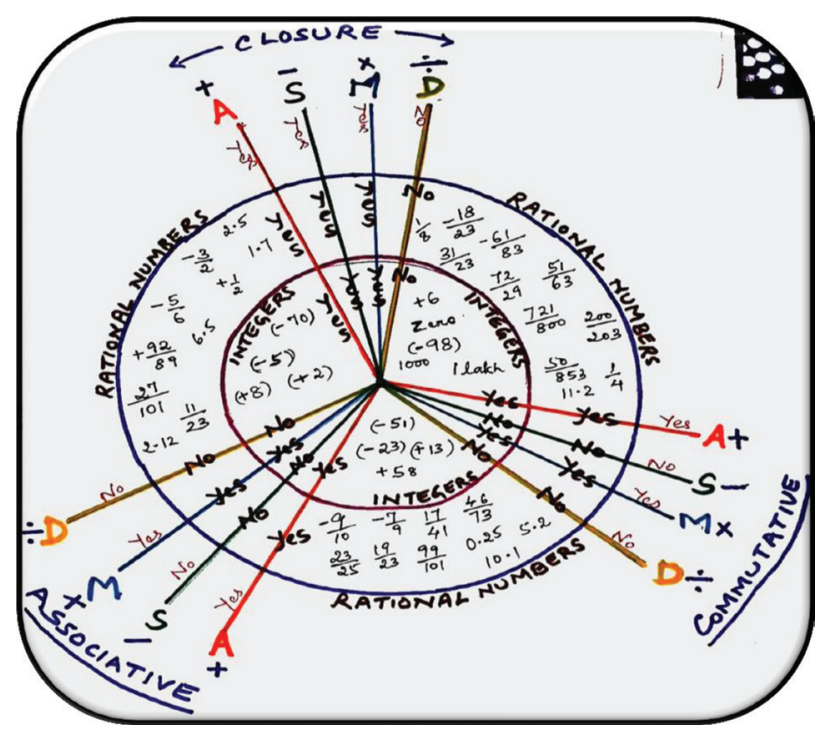

Figure 4: Pictorial aid for the story on 'Properties of integers and rational numbers'.

\subsubsection{Art Integration}

Art integration provides opportunities to study content of mathematics through different perspectives. It triggers deeper understanding, insight and exploration of the subject. It prepares a student for future life by simultaneously encouraging cognition in Maths \& awareness in arts. Use of visual language helps encode meaning through visual elements. It is a well known fact that 'Speech' as a means of human communicative activity includes visuals. Using these aptly to suit mathematical needs, for example to portray symmetric formations in dance performance, geometry of Warli paintings, the pattern of musical notes in a song, is the motive. Ably describing the perception, comprehension and production of visible signs is the extended application of visual language. Visual expression in various manifestations can go beyond traditional obstructions to any language and serve as a change agent in today's era of technology. Visual language has the potential to serve as a universally understood language. The domain of its structural units has in it, the shape, pattern, direction, orientation, colour, form, motion, texture, scale, angle, space and proportion. The concepts in a spatial context are truly represented by the elements in an image.

\subsubsection{Visual Mathematics Language- Illustration Using Examples}

The Bar Model method applies the visual representation and expression mentioned above. It is pictorial in nature and bridges the concrete to the abstract by allowing students to first visualize and understand the problem before progressing to the abstract form of numbers, notation and symbols. In this method, students learn to solve word problems by drawing either part-whole or comparison models to represent the quantities given in word problem. The use of bar models provides students to communicate their understanding of the problem, using a visual representation, which gives students a clearer idea of how the known and unknown quantities in the word problem are mutually related. It enhances students' flexibility in manipulating the given data and deciding the operations to use, hence making the understanding of the word problem more accessible and deeper. This method is a strategy to guide students' approach whilst building their mathematical reasoning capacity. During the analysis of the problem, the language flexibility is a must for the success of the method.

Example of Comparison model to solve word problems involving fractions, percentages 
Example: Jane had Rs 120. She spent (1/4) of her money on a blouse and $(2 / 3)$ of the remainder on a handbag. How much money did she have left?

First get a sense of the data, then draw a bar model to represent this data.

Step 1- Total amount of money is known. So, first draw a bar to represent the total as a whole.

4 units $=$ Rs 120

1 unit= Rs 120 divided by $4=$ Rs 30

Jane had Rs 30 left

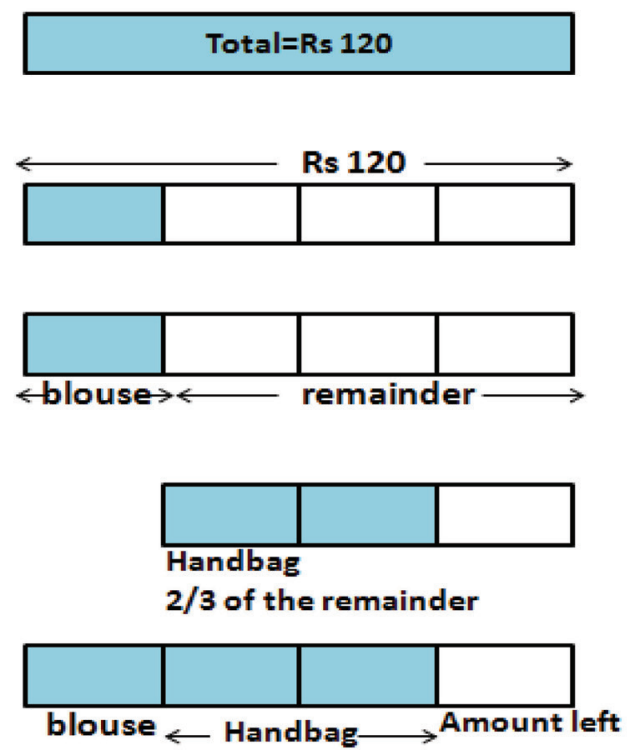

Figure 5: Bar Model Method for example problem shown above.

Pythagoras theorem verification through area of proportionate circles can be artistically depicted using 3 circular bases filled with colourful grains. Students socialize in class when they work in groups for this artistic presentation. They communicate their mathematical thinking and its applications bilingually, connect to culture.

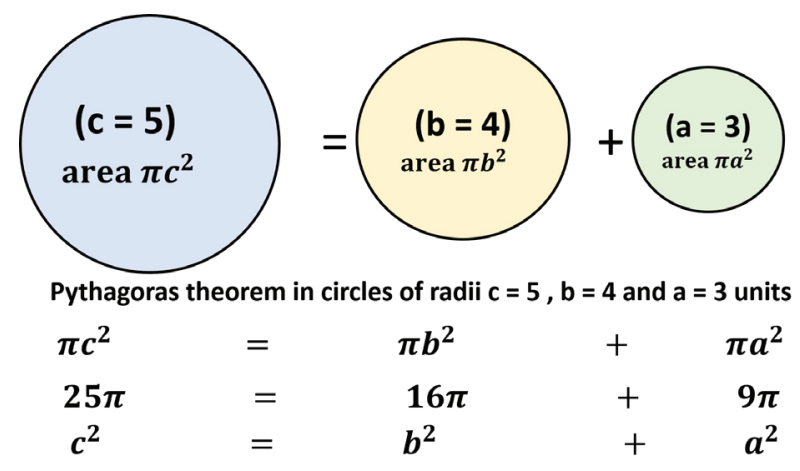



Figure 6: Pictorial representation for integrating art to Pythagoras theorem.

\subsubsection{Globally Integrated, Collaborative \& Creative Projects}

Ashift towards curricular integration and internationalism is needed for multilingual education in $21^{\text {st }}$ century. The cross disciplinary knowledge gained through 'globally integrated collaborative projects', possesses high potential to take a student to significant heights in his real life. These lead to concrete accomplishments and enable students to connect with new ideas, sources, and people. The collaborative and cooperative learning approaches encourage group learning in which 'student-grouping' is done based on their mathematics and language skills each at varying skill levels. Students exhibit greater responsibility for learning, synthesize their learning from multiple subjects, directly communicate and involve in activities with speakers of different language. The ability to spontaneously switch between three or more languages while learning mathematics is seen as a resource for communicating mathematically. 'Plurilingual approach to mathematics education', which aims at softening the boundaries between languages or cultures is a part of cross curricular education. Such innovative practices help transform the teaching learning process and target higher educational goals.

\subsubsection{Differentiated Instruction}

When mathematics is learnt in a multilingual way, in a latest pedagogical set up, the learners are exposed 
to different perspective on a single content area. Also the usage of different vocabulary simultaneously with mother tongue encourages additional associations, giving space to 'go beyond the text book'. Various flexible and Cooperative strategies involved for teaching mathematics, trigger the active approach and promise a deeper understanding of foundational concepts. The emphasis in such experiential learning is on the process of learning and not on the product, as it is inductive, learner centered and activity oriented.

The focus is on 'Independent study' wherein diversified teaching methods are purposefully provided to foster the development of individual student initiative, self-reliance, and self-improvement. Scaffolding, which supports differentiated instruction, is one of the best parts of CLIL too. Scaffolding targets on *Building on a student's existing knowledge, skills, attitudes, interests and experience ${ }^{*}$ Responding to different learning styles ${ }^{*}$ Fostering creative and critical thinking * Repacking information in user friendly ways ${ }^{*}$ Challenging students to take risks.

\section{Concluding Remarks}

A review of the development of mathematics clearly shows that ancient scholars learnt mathematics practically, being bound to day to day life. The situation provided them a need based multilingual set up for learning, which plays a significant role in conceptualization in mathematics. Today's Indian multilingual context, evidently requires similar approach to strengthen the quality of teaching learning mathematics. A planned approach to strengthen the connecting bond between different disciplines, subjects, cultures, countries can pave way for conceptualization and quality up-gradation in mathematics. Integrated curriculum has such a potential to bring in world brotherhood, cross cultural respect, tolerance, harmony, collaboration.

The comprehensive literature research reviewed in this paper, asserts that mother tongue-based multilingual math education fits well into Indian scenario. As per the analysis, the linguistic factors that positively contribute to mathematical conceptualization, must be integrated into mathematics curriculum.

\section{References}

Adler, J. (1996). Secondary School Teacher's' Knowledge of the Dynamics of Teaching and Learning Mathematics in Multilingual Classrooms. Unpublished Ph.D. thesis, Johannesburg, University of the Witwatersrand.

Adler, J. (1998). A Language of Teaching Dilemmas: Unlocking the Complex Multilingual Secondary Mathematics Classroom. For the Learning of Mathematics, 18(1), 24-33.

Baker, C. (2011). Foundations of Bilingual Education and Bilingualism. Hornberger, Nancy, H., \& Baker, C. (Eds), 3rd edition. Retrieved from

http://www.multilingual-matters.com

Benson, C. (2004). The Importance of mother tonguebased schooling for educational quality. Columbia University. Retrieved from

https://unesdoc.unesco.org/ark:/48223/pf0000146632

Benson, C. (2016). Addressing language of instruction issues in education: Recommendations for documenting progress. Retrieved from

https://unesdoc.unesco.org/ark:/48223/pf0000245575

Brantlinger, A. (2014). Critical mathematics discourse in a high school classroom: Examining patterns of student engagement and resistance. Educational Studies in Mathematics, 85(2), 201-220. https://doi.org/10.1007/s10649-013-9506-2

Brune, I.H. (1953). Language in Mathematics, In: The Learning of Mathematics: Its Theory and Practice. Washington, NTCM.

Chandler-Olcott, K., Doerr, H.M., Hinchman, K.A., \& Masingila, J.O. (2015). Bypass, Augment, or Integrate: How Secondary Mathematics Teachers Address the Literacy Demands of Standards-Based Curriculum Materials. Journal of Literacy Research, 47(4) 439-472. https://doi.org/10.1177/1086296X16632040

Cooke, B.D., \& Buchholz, D. (2005). Mathematical Communication in the Classroom: A Teacher Makes a Difference. Early Childhood Education Journal, 32(6), 365-369. https://doi.org/10.1007/s10643-005-0007-5

Darhower, M. (2002). Interactional features of synchronous computer-mediated communication in the intermediate L2 class: A sociocultural case study. CALICO journal, 19(2), 249-278. https://doi.org/10.1558/cj.v19i2.249-277

De Craen, P.V., Surmont, J., Knell, G., Stroughmayer, M., \& Struys, E. (2017). CLIL, languages of schooling and the role of implicit learning with special reference 
to the learning of mathematics. European Journal of Applied Linguistics, 6(1), 91-108. https://doi.org/10.1515/eujal-2017-0027

DiCerbo, P.A., Anstrom, K.A., Baker, L.L., \& Rivera, C. (2014). A Review of the Literature on Teaching Academic English to English Language Learners. Review of educational research, 84(3), 446-482. https://doi.org/10.3102/0034654314532695

Gardella, F.J., \& Tong, V. (2002). Linguistic considerations in the acquisition and teaching of mathematics. Word, 53(2), 185-195.

https://doi.org/10.1080/00437956.2002.11432527

Glasersfeld, E.V. (1995). A constructivist approaches to teaching. In: Steffe L.P. \& Gale J (eds). Constructivism in education. Erlbaum, Hillsdale: 3-15. Available at http://www.vonglasersfeld.com/172

Hejny, M. (2012). Exploring the Cognitive Dimension of Teaching Mathematics through Scheme-oriented Approach to Education. Orbis Scholae, 6(2), 41-55. https://doi.org/10.14712/23363177.2015.39

Henry, D.L., Nistor, N., \& Baltes, B. (2014). Examining the Relationship Between Math Scores and English Language Proficiency. Journal of Educational Research and Practice, 4(1), 11-29.

Hofmannova, M., Novotna, J. \& Moschkovich, J., (2004). Working with theories from outside mathematics education. In: 28th Conference of the International Group for the Psychology of Mathematics Education. 229-235.

John-Steiner, V., \& Mahn, H. (1996). Sociocultural approaches to learning and development-A Vygotskian framework. Educational Psychologist, 31(3/4), 191-206.

Lee, C. (2006). Language for Learning MathematicsAssessment for Learning in practice, Open University Press, McGraw-Hill Education (England).

Marsh, D. (2012). Content and Language Integrated Learning (CLIL)-A Development Trajectory. University of Córdoba. Retrieved from www.uco.es/publicaciones

Marsh, D., \& Martín, M.J.F. (2012). Introduction: Content and Language Integrated Learning. University of Jyvaskyla, Finland, \& Valencian International University, Spain.

Mehisto, P. (2008). CLIL Counterweights: Recognizing and Decreasing Disjuncture in CLIL. International CLIL Research Journal, 1(1), 93-119.

Ministry of Human Resource Development (2019). National Education Policy, (479 pages). Retrieved from https://mhrd.gov.in/sites/upload_files/mhrd/ files/Draft_NEP_2019_EN_Revised.pdf
Mishra, P., \& Mehta, R. (2017). What We Educators Get Wrong About 21st-Century Learning: Results of a Survey. Journal of Digital learning in Teacher education, 33(1), 6-19. https://doi.org/10.1080/21532974.2016.1242392

Moe, E. (2017). The language of schooling: A challenge to subject learning. Bergen language and Linguistics Studies, 7, 234-259.

https://doi.org/10.15845/bells.v7i0

Molina, C. \& Wackwitz, J. (2012). The Problem with Math Is English: A Language- Focused Approach to Helping All Students Develop a Deeper Understanding of Mathematics. Retrieved from http://www.sedl.org/pubs/catalog/items/ms108.html.

Molina, C. "Como", (2014). Teaching Mathematics Conceptually. SEDL Insights, 1(4), 1-8. Retrieved from http://www.sedl.org/insights/1-4/teaching mathematics_conceptually.pdf.

Moschkovich, J. (2005). Using Two Languages When Learning Mathematics. Educational Studies in Mathematics, 64, 121-144.

https://doi.org/10.1007/s10649-005-9005-1

Nacamulli, M. (2017). The benefits of a bilingual brain. TED Talk. Dec 11, 2017. Retrieved from https:// www.ted.com/talks/mia_nacamulli_the_benefits_ of_a_bilingual_brain?language=en

National Academies of Sciences, Engineering and Medicine (2018). English Learners in STEM Subjects: Transforming Classrooms, Schools, and Lives. Washington, DC: The National Academies Press. https://doi.org/10.17226/25182

National Council of Teacher of Mathematics (2000). Principles and standards for school mathematics. Retrieved from https://www.nctm.org/Standards-andPositions/Principles-and-Standards/

National Council of Teacher of Mathematics (2013). What Does Research Say the Benefits of Discussion in mathematics Class Are?, 1-6.

Novotna, J. \& Hofmannova, M. (2002). CLIL and mathematics education. Retrieved from https://www. researchgate.net/publication/228491266_CLIL_and_ mathematics_education

Piccardo, E. (2013). Plurilingualism and Curriculum Design: Toward a Synergic Vision. Tesol Quarterly, 47(3), 600-614. https://doi.org/10.1002/tesq.110

Piccardo, E. (2017). Plurilingualism as a Catalyst for Creativity in Super diverse Societies: A Systemic Analysis. Frontiers in Psychology, 8, 2169.

https://doi.org/10.3389/fpsyg.2017.02169 
Pimm, D. \& Keynes, Milton. (1994). Mathematics classroom language: Form, Function and Force. In: Didactics of Mathematics as a scientific discipline.

Riccomini, P.J., Smith, G.W., Hughes, E.M., \& Fries, K.M. (2015). The Language of Mathematics: The Importance of Teaching and Learning Mathematical Vocabulary. Reading \& Writing Quarterly, 31(3), 235-252. https://doi.org/10.1080/10573569.2015.1030995

Sarama, J., Lange, A.A., Clements, D.H., \& Wolfe, C.B. (2011). The impacts of an early mathematics curriculum on oral language and literacy. Early Childhood Research Quarterly, 27(2012), 489-502. https://doi.org/10.1016/j.ecresq.2011.12.002

Setati, M. (1998). Code-switching in a Senior Primary Class of Second-language Mathematics Learners. For the Learning of Mathematics, 18(1), 34-40.

Star, J.R., \& Stylianides, G.J. (2012). Procedural and Conceptual Knowledge: Exploring the Gap Between Knowledge Type and Knowledge Quality. Canadian Journal of Science, Mathematics, and Technology Education, 13(2), 169-181. https://doi.org/10.1080/1 4926156.2013 .784828
The National Research Council of the national academies (2012). Education for life and work - Guide for Practitioners. (pp.18-21). Retrieved from https:// www.nap.edu/resource/13398/dbasse_084153.pdf

Vygotsky, L.S. (1978). Mind in Society: The Development of Higher Psychological Processes. Cole, M., Steiner, V.J., Scribner, S., Souberman, E. (Eds). Harvard University Press

Wade-Leeuwen, B., \& Vovers, J., \& Silk, M. (2018). Education: Explainer: What's the difference between STEM and STEAM. npj Science of Learning Community. Retrieved from https://theconversation. com/explainer-whats-the-difference-between-stemand-steam-95713

Weiler, N. (2016). Crosstalk between left and right brain is the key to language development. The official journal of the university of California, San Francisco. (2016 issue). Retrieved from https://medicalxpress.com/ news/2016-05-crosstalk-left-brain-key-language.html

Zazkis, R. (2000). Using Code-Switching as a Tool for Learning Mathematical Language, For the Learning of Mathematics, 20(3), 38-43.

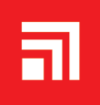 \\ CHITKARA}

\section{Issues and Ideas in Education}

Chitkara University, Saraswati Kendra, SCO 160-161, Sector 9-C, Chandigarh, 160009, India

Volume 7, Issue 2

September 2019

ISSN 2320-7655

Copyright: [` 2019 Shailaja Bairy] This is an Open Access article published in Issues and Ideas in Education (Issues Ideas Educ.) by Chitkara University Publications. It is published with a Creative Commons AttributionCC-BY 4.0 International License. This license permits unrestricted use, distribution, and reproduction in any medium, provided the original author and source are credited. 